\title{
Convective inhibition beneath an upper-level PV anomaly
}

\author{
A. Russell, ${ }^{\mathrm{a} *}$ G. Vaughan, ${ }^{\mathrm{a}}$ E. G. Norton, ${ }^{\mathrm{a}}$ C. J. Morcrette, ${ }^{\mathrm{b}}$ K. A. Browning ${ }^{\mathrm{b}}$ and A. M. Blyth \\ ${ }^{a}$ Centre for Atmospheric Science, University of Manchester, UK \\ $\mathrm{b}$ Department of Meteorology, University of Reading, UK \\ c School of Earth and Environment, University of Leeds, UK
}

\begin{abstract}
Upper-level potential-vorticity (PV) anomalies reduce the convective stability of the troposphere through their impact on the vertical potential-temperature profile, thus reducing convective inhibition (CIN) and increasing convective available potential energy. Here, by contrast, we show the impact of a layer of stable air that was intrinsically linked with an upper-level PV anomaly and that increased CIN. This layer descended and tracked beneath the small upper-level PV anomaly, which in this case was a shallow upper-level trough. This low-humidity, relatively high-PV layer originated from the tropopause fold, generated by a breaking Rossby wave, which also produced the upper-level PV anomaly two days later. Despite conditions favourable for deep convection (as demonstrated by the development of a single storm), the CIN produced by this dry layer or lid was largely responsible for capping convection over much of southern England at around $2.5 \mathrm{~km}$ during the case presented here, which comes from the Convective Storm Initiation Project. Copyright (C) 2008 Royal Meteorological Society
\end{abstract}

KEY WORDS CSIP; capping inversion; potential vorticity; tropopause fold

Received 12 May 2007; Revised 5 November 2007; Accepted 28 December 2007

\section{Introduction}

\subsection{PV anomalies and convection}

The role of upper-level potential-vorticity (PV) anomalies in reducing the convective stability of the troposphere is well established, particularly since the review of Hoskins et al. (1985). In short, the upward (downward) curvature of isentropes in the troposphere (stratosphere) associated with a moving PV anomaly leads to tropospheric ascent ahead of, and descent behind, the depressed tropopause. It is this vertical displacement of the isentropic surfaces that causes the reduction in static stability beneath the PV anomaly and, under certain conditions, can help to induce convection (e.g. Griffiths et al., 2000). Indeed, using an atmospheric model initialized with data from soundings taken through tropical, synoptic-scale cyclonic systems influenced by upper-level PV anomalies, Juckes and Smith (2000) have calculated the extent to which the PV anomaly increased convective available potential energy (CAPE) and reduced convective inhibition (CIN) in the situations examined. This convective destabilization arises from the aforementioned displacement of the isentropic surfaces in the troposphere (Hoskins et al., 1985). Further emphasizing the importance of upper-level PV anomalies in forcing convection, Roberts (2000) has shown, in a climatology of mesoscale PV maxima in the North Atlantic and Western European region, that

\footnotetext{
* Correspondence to: A. Russell, Centre for Atmospheric Science, School of Earth, Atmospheric and Environmental Sciences, University of Manchester, M13 9PL, UK.

E-mail: andrew.russell-2@manchester.ac.uk
}

such PV anomalies influence about $60 \%$ of the observed thunderstorms.

In contrast, a number of mid-latitude case studies (e.g. Browning and Hill, 1985; Griffiths et al., 1998; Browning and Roberts, 1999) have shown lower-level lids moving beneath upper-level PV anomalies and inhibiting convection. In none of these cases, however, was the lid described in any detail; nor were the processes responsible for generating the low-level CIN examined.

\subsection{Lids, CAPE and CIN}

Before moving on to consider the role and origin of such lids, we will define a number of terms used frequently throughout this paper. First, a lid (or capping inversion) is defined here as a stable layer of relatively warm, dry air that has air of higher wet-bulb potential temperature $\theta_{\mathrm{w}}$ beneath it and lower $\theta_{\mathrm{w}}$ above it in the middle and upper troposphere.

The CAPE and CIN are of most relevance in the consideration of the ascent of air parcels using the parcel method, represented on thermodynamic diagrams. The ascent in this method takes the form of a surface parcel being lifted via a dry adiabat to saturation - the lifting condensation level - followed by further ascent on a saturated adiabat. This method is particularly useful with tephigrams, which will be used in this work, as they are constructed in such a way that area is proportional to energy. Therefore, when a surface parcel ascends, the CAPE (CIN) is defined as the enclosed area bounded on the right (left) by the lifted-parcel path and on the left 
(right) by the environmental profile. In more physical terms, the CIN is the energy needed to reach the parcel's level of free convection - usually the energy required to overcome any lids - and the CAPE is the maximum energy available to the ascending parcel, both above and below any lids present. For more on these subjects, the reader is referred to Bennett et al. (2006) and Browning et al. (2007).

It is also important to discuss the role of atmospheric lids in driving the development of thunderstorms in the context of CAPE and CIN. Such ideas are discussed at greater length by Bennett et al. (2006), but we will give a brief overview here. Atmospheric-lid features can promote as well as inhibit deep convective storms. In the absence of CIN, the convection that develops is often widespread but shallow, unless the profile is unusually unstable. The presence of a lid can allow the lowest levels of the atmosphere to accumulate heat and moisture, creating the potential for deep convection. Release of this potential typically occurs at selected points along the lid when there is sufficient boundary-layer forcing (i.e. convergence or orographic uplift). Alternatively, the lid may be weakened by large-scale uplift, or there may be a combination of the two effects. This rather complex interplay between convective inhibition and deep convection is one reason why CAPE by itself is not a good predictor of thunderstorm magnitude (McCaul and Weisman, 2001).

\subsection{Tropopause folds}

To understand the observations of lids beneath PV anomalies that have been mentioned above, and will be studied in this paper in more detail, it is necessary to consider the mechanism of tropopause folding within the breaking Rossby waves that generate the upper-level PV anomalies. This process was elegantly described by Danielsen $(1964,1968)$. The important factor in this context is how upper-tropospheric and lower-stratospheric air is driven downwards and dispersed in a fan-like pattern, as shown in figure 1 of Browning (1997) - this figure was itself derived from Danielsen (1964). It is the wind field associated with the folded tropopause that causes the distinctive dispersion pattern. Deep folds develop on the western side of an upper-level trough (or PV anomaly) as the trough extends into a streamer (Appenzeller and Davies, 1992) or cut-off low (COL) - i.e. as the Rossby wave breaks. Danielsen showed how the trajectories of air passing through the fold fan out at the base of the trough, with air on the westernmost edge turning anticyclonically away from the trough while air further up the fold (to the east) turns cyclonically around it. The latter branch is of interest here, for it produces a layer of very dry, stable air that follows behind the cold front of the downwind weather system, forming part of the dry intrusion (Browning, 1997). An illustration of a fold occurring over the UK, as an upper-level trough extended into a COL over Spain, was presented by Vaughan et al. (1994). Satellite images showed arcs of convection at the leading edge of the anticyclonically-curving trajectories west of Morocco, while deep convection developed in the eastern sector of the COL (over eastern Spain). However, the impact of the branch of the fold that travelled eastward around the COL was not examined in that study.

\subsection{Relevance and structure of this paper}

Because of their synoptic scale, the development of upper-level PV anomalies is generally well represented in numerical weather-prediction models (e.g. Clark and Lean, 2006), and the resulting effect on convection is often readily forecast. However, even relatively small errors in the upper-level PV field in such models can have a substantial impact on the resulting precipitation projections (e.g. Fehlmann et al., 2000). Therefore, to fully understand the impact of upper-level PV anomalies, it is necessary to examine cases that do not result in much significant convective development, as well as those that do, and, if only limited convection is observed, why this is. This is the aim of this paper. We present an example of a lower-level lid beneath a PV anomaly, which played a role in confining convection beneath about $2.5 \mathrm{~km}$ over the southern UK. Despite this widespread CIN, however, a single isolated thunderstorm did occur during this case, where the combination of lifting (and increase in CAPE) due to the upper-level PV anomaly and a surface convergence line overcame the CIN due to the lid. This convective development has been investigated at length by Morcrette et al. (2007); so this paper examines the source of the convective inhibition and, in particular, the development and role of the lid.

The paper is structured as follows. In Section 2 we introduce the datasets that will be used in the case study. In Section 3 we present an examination of the tropospheric convective stability on 15 June 2005, and show how it was related to the observed atmospheric features, i.e. the upper-level PV anomaly and the dry layer or lid. We then consider the origin of these features within a breaking Rossby wave over the Atlantic, and how their movement towards the UK was influenced by the jet stream over the Atlantic and a surface front (Section 4). Finally, we discuss the implications of this case study (Section 5), and draw conclusions (Section 6).

\section{Data}

The event investigated here occurred on 15 June 2005, during the Convective Storm Initiation Project (CSIP). Observations were taken around Chilbolton, Hampshire $\left(51.2^{\circ} \mathrm{N}, 1.4^{\circ} \mathrm{W}\right.$ - see Figure 1 for the location of places referred to in the text) by a network of instruments, as summarized by Browning et al. (2007). Here, we will present data from the following sources: CSIP and UK Met Office radiosondes; the Mesosphere-Stratosphere-Troposphere (MST) radar (Vaughan, 2002), which is located near Aberystwyth, Wales $\left(52.4^{\circ} \mathrm{N}, 4.0^{\circ} \mathrm{W}\right)$; ECMWF analyses; back trajectories derived from ECMWF analyses; UK Met Office 
surface synoptic charts; the Total Ozone Mapping Spectrometer (TOMS) (Heath et al., 1975); the Meteosat Second Generation (MSG) satellite (Schmetz et al., 2002); the Chilbolton $3 \mathrm{GHz}$ Advanced Meteorological Radar (CAMRa); and the Universities' Facility for Atmospheric Measurements (UFAM) UHF wind profiler (Norton et al., 2006). The last of these instruments - the UHF windprofiling radar - operates at $1290 \mathrm{MHz}(23 \mathrm{~cm}$ wavelength) with three beams: one pointing to the zenith, and two at $17.5^{\circ}$ off-vertical. Echoes are obtained from refractive-index inhomogeneities in clear air and from raindrops. The turbulent convective boundary layer is full of structure in refractive index, and therefore gives a strong echo; layers with sharp gradients in absolute humidity and potential temperature (such as are found in atmospheric lids) also show up as layers of enhanced echo power because of the fractal nature (i.e. a cascade of scales) of the gradients (Muschinsky and Wode, 1998) - the radar is sensitive to structure on the scale of half its wavelength. The combination of these datasets will illustrate the development of a breaking Rossby wave, the associated tropopause fold, the resultant upperlevel PV anomaly, and the dry layer that caused the CIN beneath the PV anomaly.

\section{Convective stability of the troposphere over the UK}

\subsection{Synoptic background}

The CSIP Intensive Operation Period 1 (IOP1), 15 June 2005 , was characterized over the southern UK by two consecutive meteorological regimes. Initially, the main event was the passing of an active split front (Browning and Monk, 1982) in the morning, which brought with it some rain (accumulation of about $9 \mathrm{~mm}$ at Chilbolton for the period 0500-1000 UTC). Secondly, an isolated thunderstorm (maximum rainfall rate of $32 \mathrm{~mm} \mathrm{~h}^{-1}$ ) developed over southern England between 0900 and
1200 UTC, reaching maximum intensity near Oxford $\left(51.6^{\circ} \mathrm{N}, 1.3^{\circ} \mathrm{W}\right)$ at $1200 \mathrm{UTC}$. The general direction and growth of the storm is indicated in Figure 1. The convective initiation of this storm was linked, principally, to a topographically-induced convergence line orientated southwest-northeast over southern England, and to a reduction in convective stability associated with a small upper-level trough, or PV anomaly, that moved from east to west over the UK (Figure 2). The development of this storm is discussed in greater detail by Morcrette et al. (2007), but of more general importance was the suppression of more widespread convection beneath $2.5 \mathrm{~km}$ over the rest of the southern UK at a time when CAPE values were enhanced by the PV anomaly. This is the focus of the present paper.

\subsection{Contribution of the PV anomaly to the CAPE}

The influence of the PV anomaly on the tropospheric stability is most effectively shown by a profile of potential temperature from a series of radiosondes (Figure 3) launched on 15 June 2005 from Larkhill, Wiltshire $\left(51.2^{\circ} \mathrm{N}, 1.8^{\circ} \mathrm{W}\right)$. The isentropes show a clear region of reduced convective stability (i.e. a weak vertical $\theta$ gradient) beneath the depressed tropopause at 1000 UTC, particularly between $400 \mathrm{hPa}$ and $700 \mathrm{hPa}$. Most of this area is shaded in Figure 3: this indicates that it is a region of CAPE, and relates to the contribution to the CAPE derived from the upper-level cold pool (Hill and Browning, 1987). This region of CAPE is also clearly seen in the individual Larkhill sounding for 1000 UTC (Figure 4(a)). Furthermore, from consideration of the second shaded (CAPE) region of Figure 3 - near the surface for the period 1000-1600 UTC - it can be determined that there was CAPE, and very probably convection, beneath about $2.5 \mathrm{~km}$ at Larkhill. These are clearly conditions under which deep convection could have occurred (temporally coincident CAPE in the upper and lower troposphere); however, as Figure 1 shows, Larkhill was

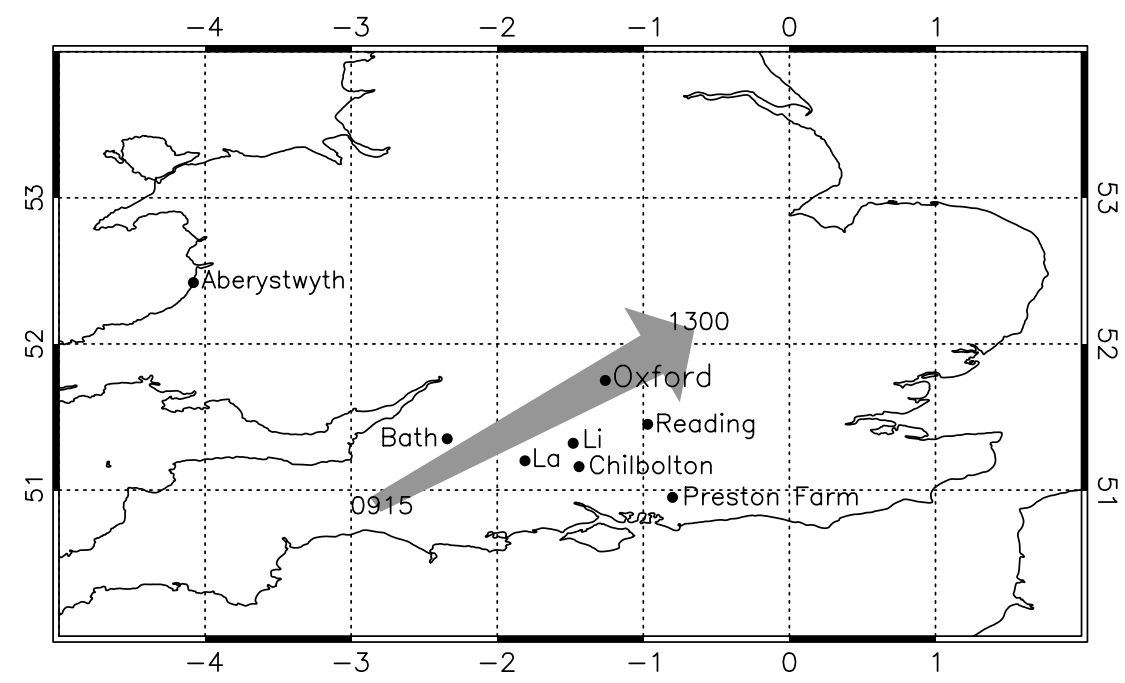

Figure 1. Map of southern Britain showing the locations of the places referred to in the text. 'La' is Larkhill and 'Li' is Linkenholt. The large grey arrow indicates the approximate path and growth of the storm from 0915 to 1300 UTC while it was being tracked by the Chilbolton radar. 

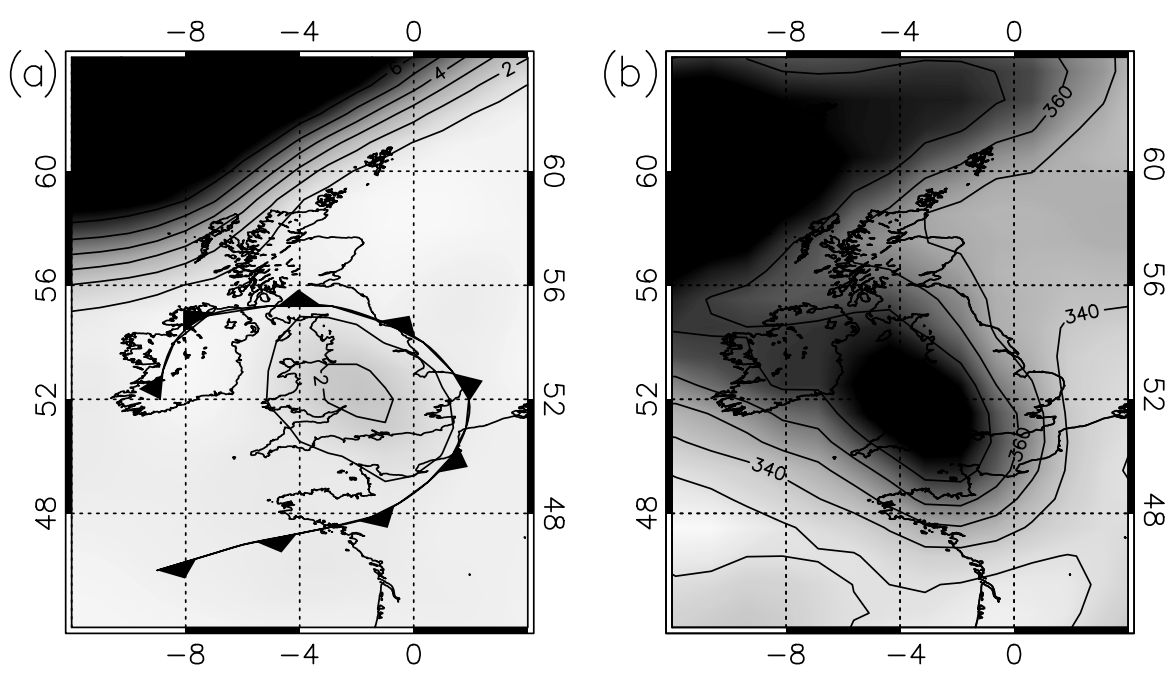

Figure 2. The small upper-level PV anomaly: (a) ECMWF operational analysis of PV on the $315 \mathrm{~K}$ isentropic surface for $1200 \mathrm{UTC}$ on 15 June 2005 (in PV units, i.e. $1.0 \times 10^{-6} \mathrm{~m}^{2} \mathrm{~s}^{-1} \mathrm{~K} \mathrm{~kg}^{-1}$ ); (b) total ozone (in Dobson units, DU) for approximately $1130 \mathrm{UTC}$ on $15 \mathrm{June} 2005$ from TOMS (contours are every $20 \mathrm{DU}$ ). The TOMS data are indicative of the tropopause depression associated with the PV anomaly, as the total ozone column detected by the spectrometer is enhanced by the intrusion of stratospheric, high-ozone air to lower levels than usual; the PV anomaly results in the stretching of the small vortex into the upper troposphere. Darker shading in panels (a) and (b) indicates higher levels of $\mathrm{PV}$ and $\mathrm{O}_{3}$ respectively. The feature was moving from east to west at about $56 \mathrm{~km} \mathrm{~h}^{-1}$.

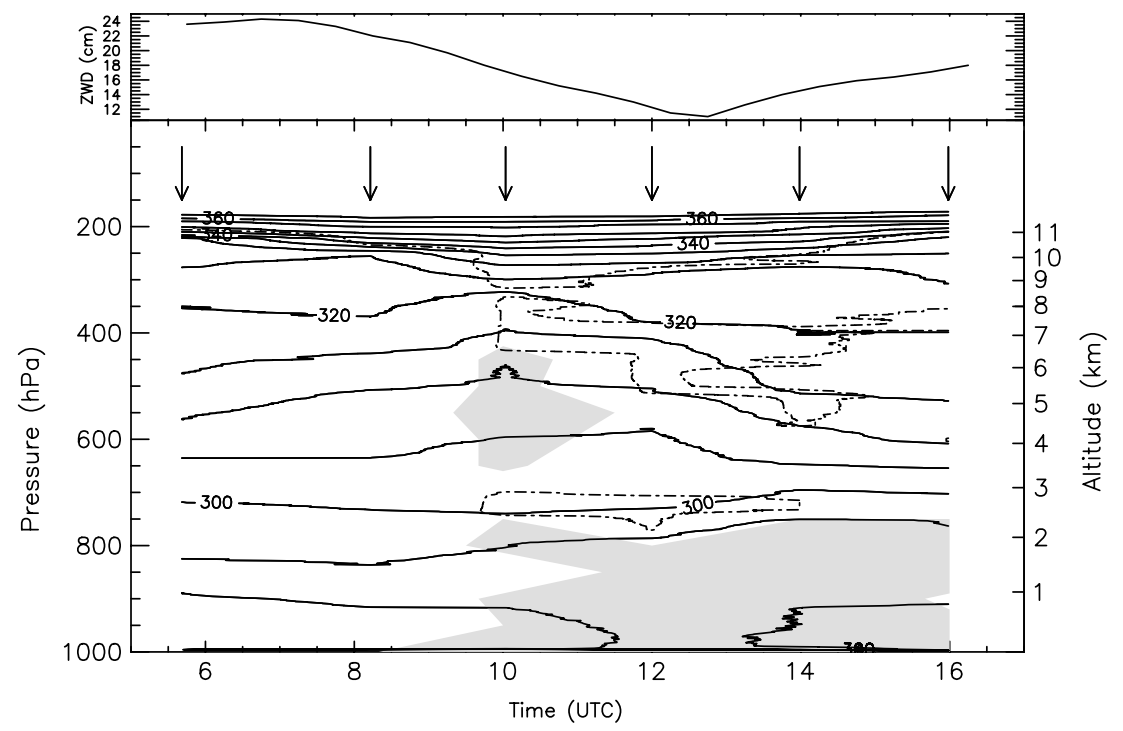

Figure 3. Potential temperature $\theta$ (solid lines, contour interval $5 \mathrm{~K}$ ), and the $10 \%$ relative-humidity contour (dash-dotted lines), derived from six Larkhill $\left(51.3^{\circ} \mathrm{N}, 1.4^{\circ} \mathrm{W}\right)$ soundings for 15 June 2005 . The 1002 UTC sounding from this profile can be seen individually as Figure 4(a). Shading indicates regions that contribute to the CAPE of the individual profiles (i.e. where the surface value of $\theta_{\mathrm{w}}$ minus $\theta$ at each level is positive (Morcrette et al., 2007)). The arrows indicate the radiosonde release times. The smaller top plot shows atmospheric water vapour (calculated in centimetres of zenith wet delay) derived from a GPS station at nearby Thruxton $\left(51.2^{\circ} \mathrm{N}, 1.6^{\circ} \mathrm{W}\right)$.

outside the region where the storm did develop. In an effort to explain this, it is notable that the profile of the $10 \%$ relative humidity $(\mathrm{RH})$ contour (Figure 3 ) shows a dry, stable layer at approximately $700 \mathrm{hPa}$, or $2.5 \mathrm{~km}$. We propose that this dry layer, or lid, was responsible for limiting convection to beneath $2.5 \mathrm{~km}$ over much of southern England on this day. Indeed, Figure 4(a) shows that the capping inversion was just strong enough to have contained the ascent of the air parcel from the surface. Given that no storms initiated through this point, it can be assumed that the lid did halt the convection, but more evidence is required to substantiate this claim.
3.3. Observations and role of the lid and the tropopause fold

The capping effect of the lid identified in Figure 3 can be seen particularly clearly in the signal-to-noise-ratio data from the UFAM wind profiler (Figure 5(a)). The instrument was located at Linkenholt, Hampshire $\left(51.3^{\circ} \mathrm{N}\right.$, $1.5^{\circ} \mathrm{W}$ ), just on the boundary between the path of the developing storm and the region of limited convection. The details of how this radar depicts convection and stable layers can be found in the caption to Figure 5 and in Section 2. Two layers of enhanced echo power are visible in Figure 5(a): one at around $1 \mathrm{~km}$ from 1000 to 

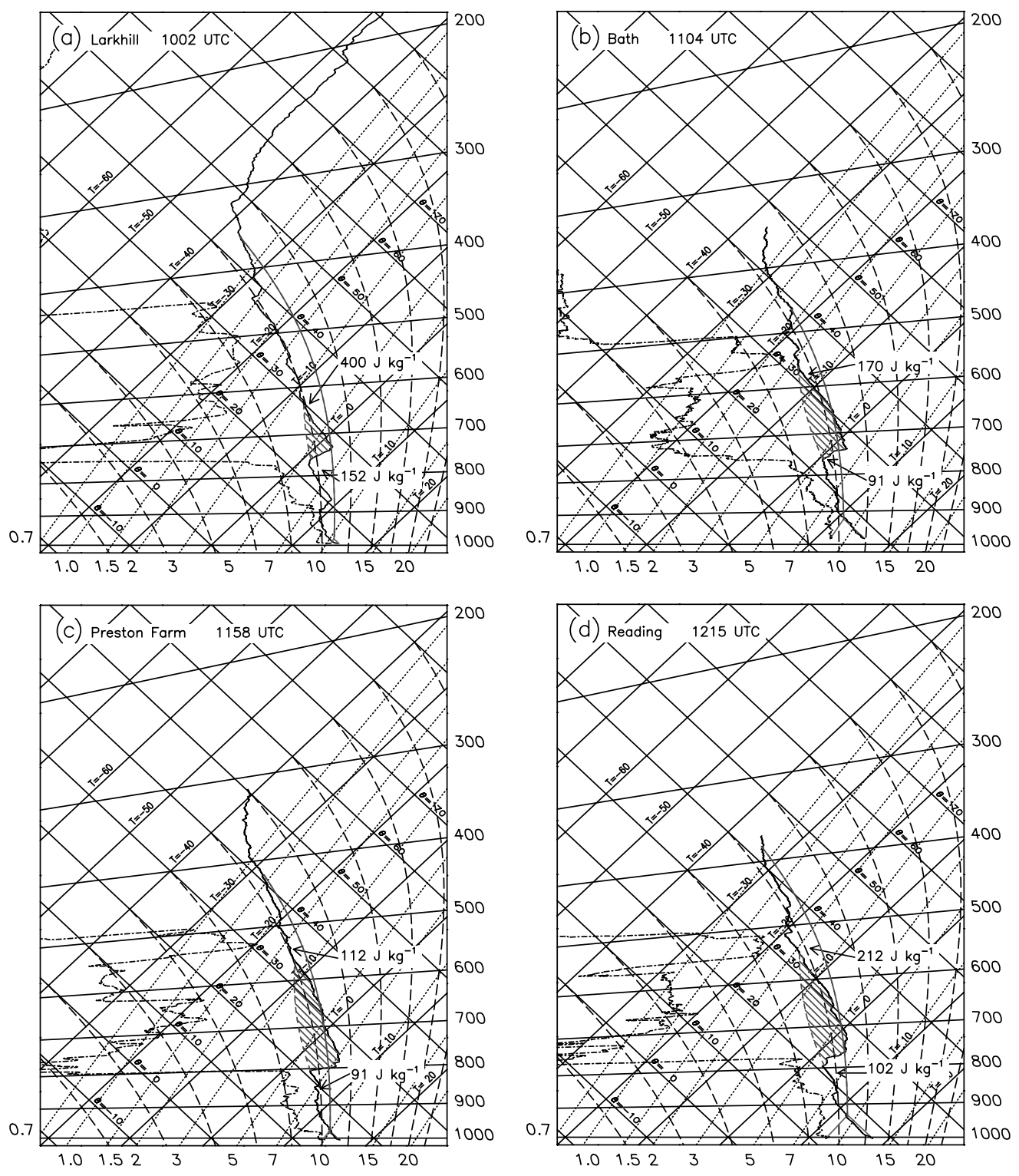

Figure 4. Radiosonde ascents from: (a) Larkhill at 1002 UTC; (b) Bath at 1104 UTC; (c) Preston Farm at 1158 UTC; (d) Reading at 1215 UTC. The solid lines show potential temperature $\theta$, and the dash-dotted lines show dew-point temperature $T_{\mathrm{d}}$. The hatched areas indicate how the profiles of $\theta$ would be altered if the dry lid at each location were removed. The grey dashed line shows the $\theta_{\mathrm{w}}$ line associated with the surface parcel ascent for each sounding. The CAPE value above and below the lid has been calculated after Emanuel (1994).

1200 UTC, and another between $2 \mathrm{~km}$ and $2.5 \mathrm{~km}$ from 1000 UTC onwards. These layers can be understood by considering the numbered regions of Figure 5(a), which correspond to: (1) the precipitation associated with the passing front, which resulted in the loss of radar data due to aliasing for just under an hour; (2) the growth of the turbulent boundary layer, after the passage of the front, breaking through the low-level inversion, seen at $875 \mathrm{hPa}$ on Figure 4(a), at around midday; and (3) the suppression of further boundary-layer growth and convection to higher levels by the second inversion at $2.5 \mathrm{~km}$ - this layer is identified as the aforementioned lid seen in Figure 3 (Linkenholt and Larkhill are only $24 \mathrm{~km}$ apart). This lid was also identified by Morcrette et al. (2007), who analysed data from the scanning UHF and S-band radars at Chilbolton. They showed that the lid covered a much wider area than merely Linkenholt and Larkhill, as is also shown in Figures 4 and 8, and that where this lid was broken by the convection, the storm reached at least as high as $7 \mathrm{~km}$. Figure $5(\mathrm{~b})$ is an example of a rangeheight indicator (RHI) from the S-band Chilbolton radar (CAMRa) used by Morcrette et al; it shows the signal return from the lid itself, and some developing convective elements that were capped by it. Note that the convection at Linkenholt did not reach the $2.5 \mathrm{~km}$ inversion until 1300 UTC, by which time the upper-level PV anomaly had passed overhead. Therefore the potential for deep convection had ceased at this location. Nonetheless, the UFAM wind profiler does provide a graphic illustration of the convective inhibition by the lid on this day.

Further examination of Figure 3 reveals another region of dry air (RH less than 10\%) sloping down from the depressed tropopause as a stable layer after 1100 UTC. This feature is a tropopause fold, i.e. a region where the 

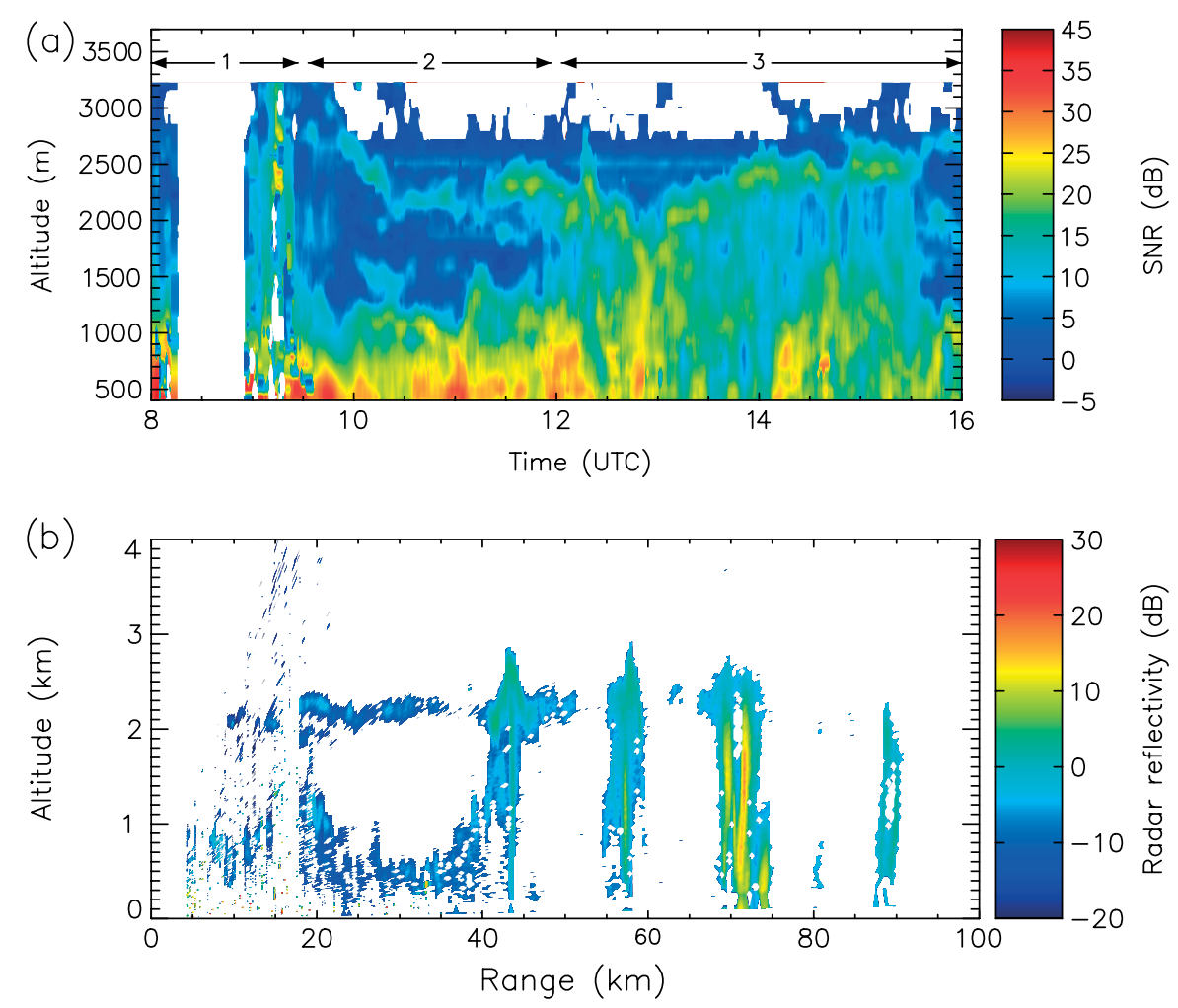

Figure 5. Observations of the lid. (a) The signal-to-noise ratio, in decibels, measured by the University of Manchester UFAM wind profiler between 0800 and 1600 UTC on 15 June 2005. Under conditions free of precipitation, the radar echo power depends on refractive-index (RI) inhomogeneities. These can be caused either by vertical gradients in potential temperature and specific humidity (as for the MST radar, Figure 7) or by active turbulence, mixing together air of differing RI. Both effects are seen here: the layer between $2 \mathrm{~km}$ and $2.5 \mathrm{~km}$ is the air mass gradient associated with the lid; and the growth of high echo power from lower levels during the day represents the growth of the convective boundary layer. The regions labelled 1, 2 and 3 are discussed in the text. (b) The radar reflectivity from an RHI scan of the CAMRa at 1119 UTC along an angle of $293^{\circ}$. The signal from the lid can be seen horizontally at around $2.2 \mathrm{~km}$, and the signal from four vertical convective features can be seen near the $40 \mathrm{~km}, 55 \mathrm{~km}, 70 \mathrm{~km}$ and $90 \mathrm{~km}$ ranges. Only one of these elements developed into the storm near Oxford: this was the one near the $55 \mathrm{~km}$ range. This figure is available in colour online at www.interscience.wiley.com/qj

dynamic tropopause (the 2 PVU contour) folds back on itself. This is corroborated by Figure 6. The presence of this feature will be useful in determining the history of the tropopause depression in Section 4. Figure 3 also shows the water-vapour (WV) content of the atmospheric column above Thruxton, Hampshire $\left(51.2^{\circ} \mathrm{N}, 1.6^{\circ} \mathrm{W}\right)$, as calculated from the GPS station there: see Bevis et al. (1992) for the details of this calculation. These data confirm how the lowering of the tropopause was accompanied by a reduction of atmospheric WV, with the lowest values at the trailing end of the PV anomaly as a result of descent behind the deepest portion of the tropopause depression and the dry air intruding into the troposphere via the fold.

The passage of the upper-level trough is shown clearly by measurements from the MST radar (Figure 7). This VHF radar, operating at a frequency of $46.5 \mathrm{MHz}$ (wavelength $6.41 \mathrm{~m}$ ), is able to observe higher in the atmosphere than the UFAM wind profiler, and is much less sensitive to precipitation: echo power is due almost entirely to quasi-specular reflection from gradients in static stability and specific humidity (Gage and Green, 1981). Vaughan et al. (1995) showed that the tropopause may be identified in MST radar data as the base of the layer of increased echo power in the lower stratosphere.
Thus, the leading edge of the upper-level PV anomaly can be inferred from Figure 7(b) as the point where the tropopause descends from $10 \mathrm{~km}$ to $9 \mathrm{~km}$ at $0800 \mathrm{UTC}$, and its trailing edge at 1040 UTC as the point where the tropopause begins to ascend again. Characteristically, the echo-power minimum in the upper troposphere becomes much less prominent during the PV anomaly, as the stretching of the tropopause in a cyclonic region causes an indistinct thermal tropopause (Bethan et al., 1996). On both sides of the trough, but most prominently behind it, is a tropopause fold, evident as a layer of enhanced vertical wind shear descending to lower levels (Figure 7(a)). Allowing for the east-west distance between Aberystwyth and Larkhill (about $200 \mathrm{~km}$ ) and the speed of the upper-level PV anomaly $\left(56 \mathrm{~km} \mathrm{~h}^{-1}\right.$, determined from a series of MSG images), we can conclude that this descending feature is also visible in Figure 3 as the dry layer extending down behind the upper-level PV anomaly from around 1100 UTC. Furthermore, we can see that the descending air associated with this fold was responsible for the increased stability seen at about $700 \mathrm{hPa}$ after 1400 UTC in Figure 3. This descent continued to inhibit convection in the same region as the lid throughout the remainder of the day, and is the reason why no CAPE is visible in Figure 3 above the lid after 1200 UTC. 


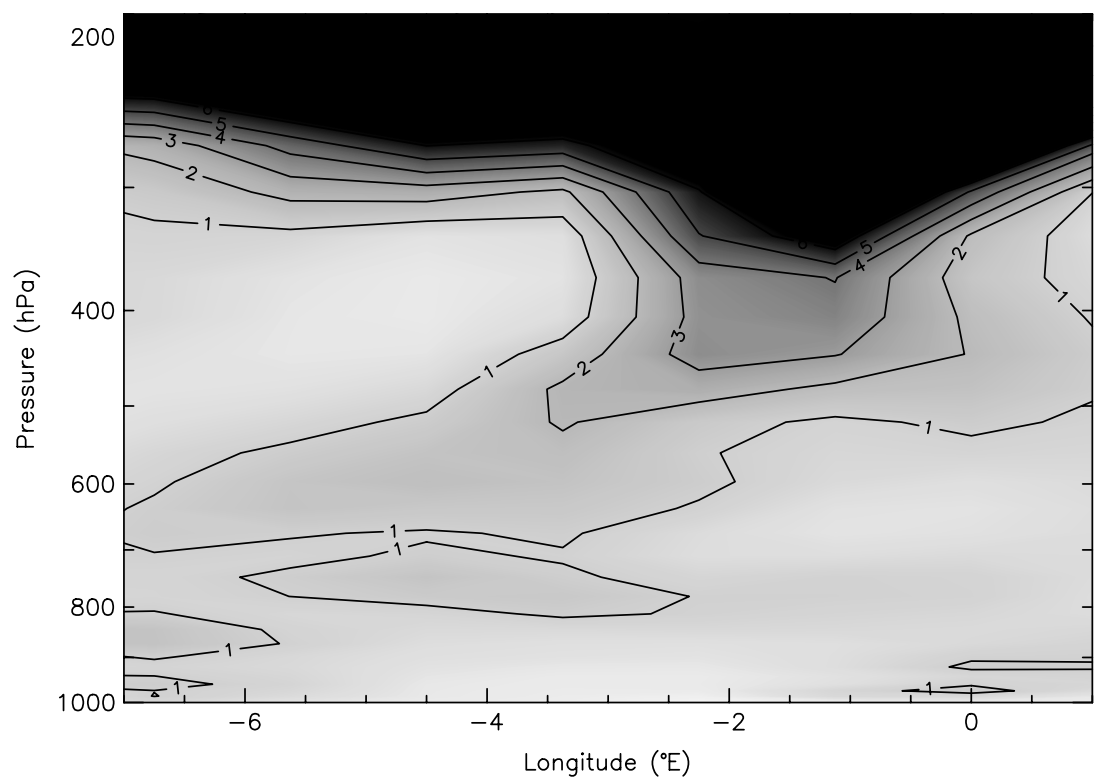

Figure 6. The small upper-level PV anomaly shown as a vertical cross section through $52^{\circ} \mathrm{N}$. The data are from the ECMWF operational analysis of PV (in PV units) for 1200 UTC on 15 June 2005.
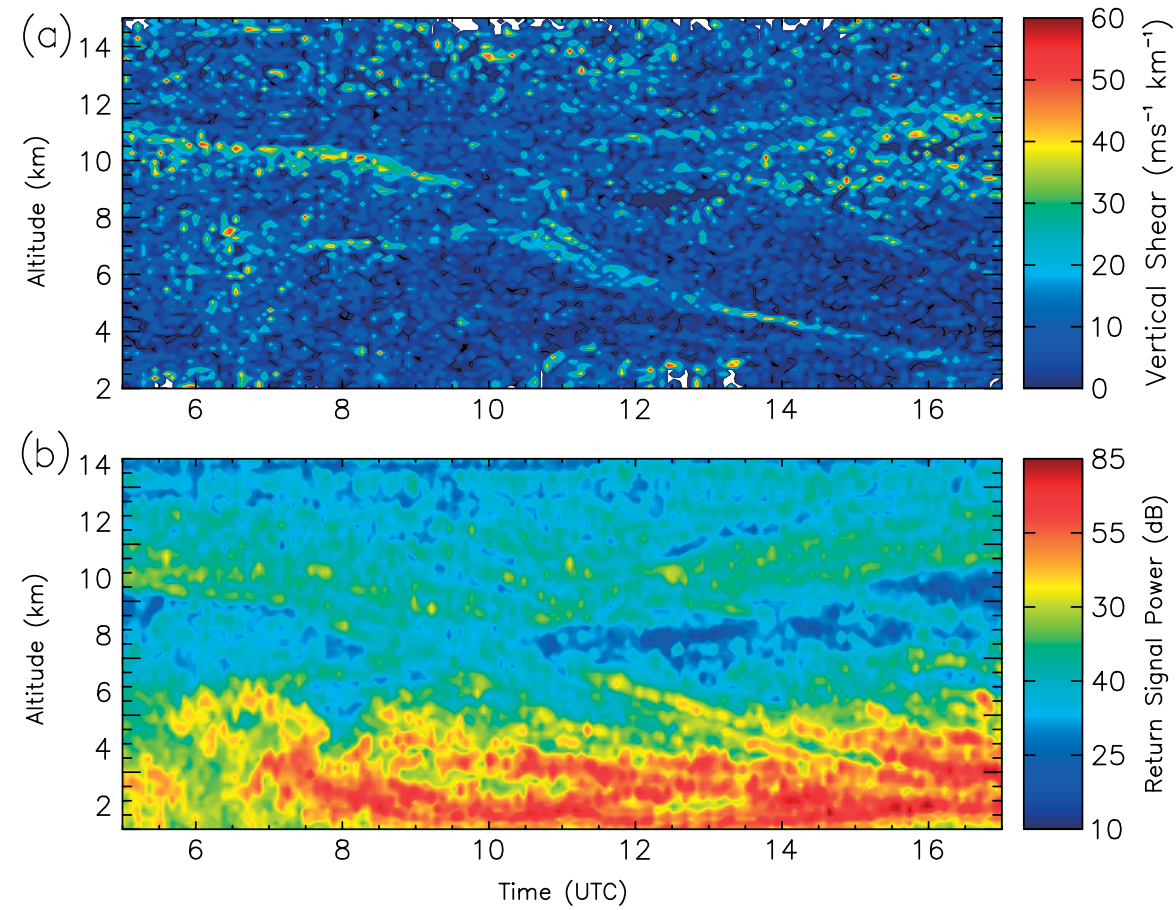

Figure 7. Data from the MST radar for 15 June 2005, showing the period 0500-1700 UTC below $15 \mathrm{~km}$ : (a) vertical shear; (b) radar return signal power. This figure is available in colour online at www.interscience.wiley.com/qj

The vertical shear (Figure 7(a)) also shows a thin layer of high values between $2 \mathrm{~km}$ and $3 \mathrm{~km}$ between 1000 and 1400 UTC. From consideration of the radar verticalvelocity data (not shown) and the distinctive shape of these small vertical-shear maxima, it is likely that this feature is related to convection, and not the lid that we have previously examined, despite being at the same altitude.

The extent of the lid is more clearly defined by consideration of Figure 8(a), which shows a visible image from the MSG satellite at 1200 UTC. This indicates that there was a tongue of cloud-free air sweeping over southern England from the Atlantic. The ECMWF operational analysis (Figure 8(b)) shows a corresponding tongue of very dry air (RH less than $20 \%$ ) at $700 \mathrm{hPa}$, which relates to the dry layer in Figure 3. The impact of, and the area affected by, the lid can also be illustrated by examining individual radiosonde ascents from the CSIP area. Figure 4 shows the range of locations affected by the capping inversion: Larkhill, Bath, Preston Farm 

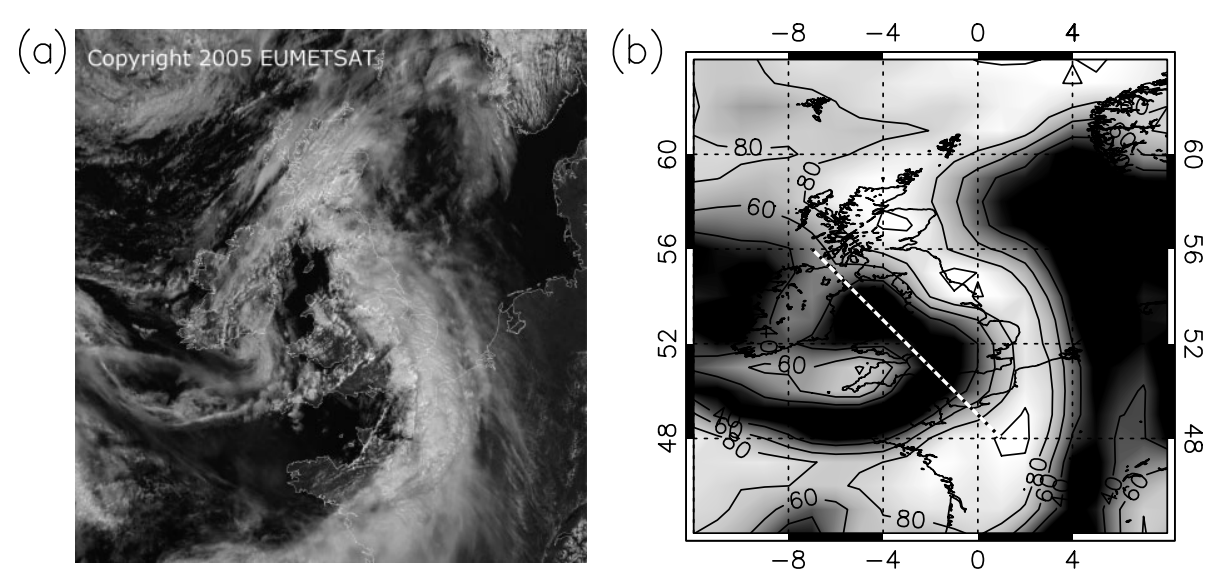

Figure 8. The horizontal extent of the lid at 1200 UTC on 15 June 2005. (a) Visible MSG image, showing the front with its rear edge curving from Nantes up to Liverpool, and two convergence lines: one extending north-northeast from Cornwall, and the other lying over the Cherbourg peninsula. Between the convergence lines, extending westwards, is a clear, probably dry, region. This clear region represents the extent of the lid that is being examined in this work. (b) RH on the $700 \mathrm{hPa}$ surface, from the ECMWF operational analysis, showing the extent of the inferred dry region from Figure 8(a) in more detail. The dashed line shows the location of the cross section plotted in Figure 9.

and Reading (see Figure 1). These data are consistent with Figures 3, 5 and 8, in that they all show the lid at around $2.5 \mathrm{~km}$ and an ascending surface parcel would be unable to break through the lid in each case. It is also clear that the inversion is a very dry feature in each sounding. Furthermore, it can be seen that the greatest CIN was present at Preston Farm (the furthest sounding from the path through which the storm developed - see Figure 1), the CIN values being $4 \mathrm{~J} \mathrm{~kg}^{-1}$ for Larkhill, $30 \mathrm{~J} \mathrm{~kg}^{-1}$ for Bath, $42 \mathrm{~J} \mathrm{~kg}^{-1}$ for Preston Farm, and $13 \mathrm{~J} \mathrm{~kg}^{-1}$ for Reading. This is consistent with the result of Morcrette et al. (2007), who compiled a map of lid height from RHI scans from CAMRa; the lid was higher (i.e. weakened and lifted) through the region where the storm developed, and lower as the scans moved away from the path of the storm. It is also evident that, had the lid been broken at any of these radiosonde locations, the surface parcels would have risen well into the middle or upper troposphere to levels similar to those seen for the storm itself (around $7 \mathrm{~km}$ ).

From Figure 4, we can also state that if the lid had been instantaneously removed from each of these locations, then deep convection would have been much more widespread over the southern UK. This is for two reasons: first, the lid inhibited convection in all four cases (see the saturated adiabat associated with each surfaceparcel ascent); and secondly, if the lid is removed from each sounding (as indicated by the hatched areas of Figure 4), the CAPE increases by $68 \mathrm{~J} \mathrm{~kg}^{-1}, 265 \mathrm{~J} \mathrm{~kg}^{-1}$, $265 \mathrm{~J} \mathrm{~kg}^{-1}$ and $258 \mathrm{~J} \mathrm{~kg}^{-1}$ at Larkhill, Bath, Preston Farm and Reading respectively. However, as argued in Section 1, this thought experiment does not tell the whole story. If the lid had not existed in the first place, convection would not have been capped at $2.5 \mathrm{~km}$, and the build-up of CAPE in the boundary layer required for deep convection would not have happened either. It is likely that the result would have been widespread showers, much shallower than the one storm that did occur.
The area of coverage of this dry tongue (Figure 8 ) is consistent not only with the radiosondes (Figure 4) but also with vertical cross sections of RH and PV (Figure 9) plotted along the dotted line in Figure 8(b). The RH cross section shows the descending fold and the lid extending all the way along the dry slot in Figure 8(a). The PV in the lid does not show stratospheric values, but its morphology is consistent with the $\mathrm{RH}$ data, and the limited vertical resolution of the model precludes the representation of a thin layer of enhanced static stability. The minimum value of $\mathrm{RH}$ in the lid is below $20 \%$, which, as we will discuss further in the next section, corresponds to descent from at least $400 \mathrm{hPa}$. Comparing these cross sections with Figure 7(a), it is clear that the convection observed by the MST radar between 1200 and 1300 UTC was capped by the dry lid at around $3 \mathrm{~km}$, and the apparent merging of the lid and the fold at the end is consistent with the descent of the shear layer to $3 \mathrm{~km}$ at $1600 \mathrm{UTC}$ in the radar data. We conclude that the extent of the lid was as shown by the commashaped swirl of dry air in Figure 8(b). Consistent with this, the lid is not seen in the 1200 UTC sounding from Camborne, Cornwall $\left(50.2^{\circ} \mathrm{N}, 5.3^{\circ} \mathrm{W}-\right.$ not shown), but can be observed in the 1200 UTC sounding from Brest, France $\left(48.5^{\circ} \mathrm{N}, 4.4^{\circ} \mathrm{W}\right.$ - not shown), as would be expected from the position of the dry tongue depicted in Figure 8(b). Figure 9(b) also confirms that the model represents the lid as a separate feature from the fold above it; the significance of this will be discussed further in the next section.

\subsection{Summary}

In this section we have shown, from a series of radiosonde ascents (Figure 3), that the passage of a small upper-level PV anomaly over the UK reduced the convective stability of the troposphere. Convection was suppressed over much of southern England by a lid beneath the upper-level PV anomaly. Given that the lid was very 

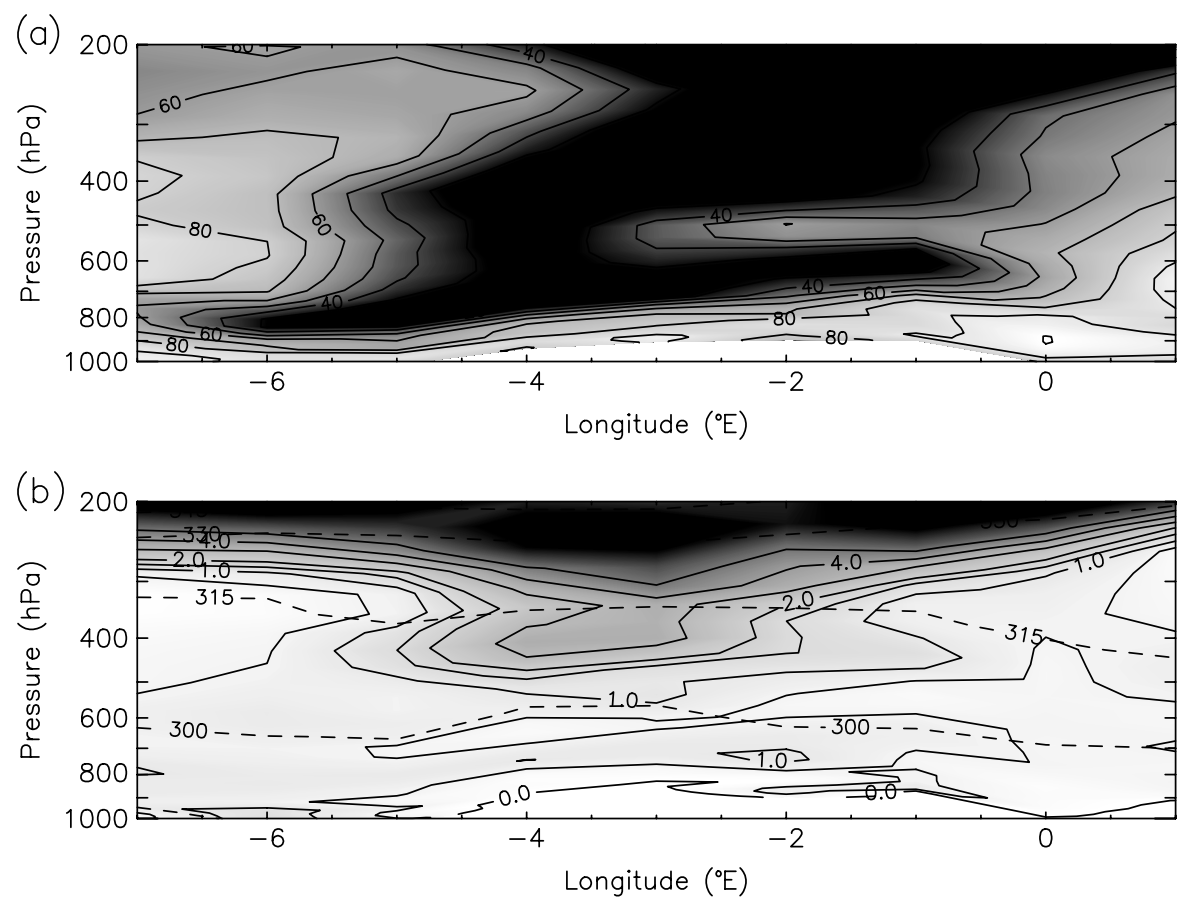

Figure 9. Vertical cross sections plotted along the line shown in Figure $8\left(\right.$ b), i.e. from $\left(54^{\circ} \mathrm{N}, 7^{\circ} \mathrm{W}\right)$ to $\left(46^{\circ} \mathrm{N}, 1^{\circ} \mathrm{E}\right)$. (a) RH from the ECMWF operational analyses. The contour interval is $5 \%$ and darker regions indicate lower RH. (b) PV (solid contours) and $\theta$ (dashed contours) from the ECMWF operational analyses. The contour interval for PV is 1 PVU and darker regions indicate higher PV.

dry (Figures 3, 4, 8 and 9(a)) and had PV values above the background (Figure 9(b)) - both indicators of a possible upper-level origin for this layer - we will next consider the source of the lid, in particular to determine if and how it was related to the PV anomaly above it.

\section{Development of the upper-level PV anomaly and the dry lid}

\subsection{General synoptic development}

The important synoptic-scale events in the build-up to CSIP IOP1 occurred over the Atlantic during the period 10-14 June 2005. The principal ingredients of the atmosphere over the area of interest in the UK on IOP1 can be traced back to a breaking Rossby wave over the Labrador Sea and the western North Atlantic. This breaking Rossby wave is well represented by plots of PV on the $315 \mathrm{~K}$ isentropic surface, as shown in Figure 10. Figure 10(a) shows the initial streamer (Appenzeller and Davies, 1992) merging with a small COL remaining over the Atlantic from a previous event. UK Met Office surface analyses for this period (not shown) highlight a surface low located just at the tip of the breaking wave. The merging of the streamer and the COL and interaction with the jet stream appear to have amplified the southward motion of the streamer (Figure 10(b,c)), and during the following days (Figure 10(d,e)) we see that a large portion of this streamer separated southwards and eastwards to leave a large new COL over the Atlantic. This large COL (and a second COL seen over the northern UK) were associated with large, stationary surface lows (both around $985 \mathrm{hPa}$ ) and a rather complex arrangement of surface fronts. The evolution of this wave followed the second life-cycle category (LC2) of Thorncroft et al. (1993). On 14 June, baroclinic development occurred on the southeastern flank of the COL in the mid-Atlantic, leading to the extrusion of a small upper-level PV anomaly behind a surface front propagating eastwards towards the UK (Figure 10(e,f)).

The $300 \mathrm{hPa}$ geopotential chart for $1200 \mathrm{UTC}$ on 15 June (Figure 11) shows the PV anomaly to be a small, shallow upper-level trough moving eastwards at relatively high speed as a small wave in the jet stream. (The jet stream can be interpreted as the region of tight geopotential height isolines that 'snakes' from approximately $45.0^{\circ} \mathrm{N}, 60.0^{\circ} \mathrm{W}$, around the southern edge of the COL, and then towards, and eventually over, the UK.) It is this small upper-level PV anomaly that can be clearly seen over the UK on 15 June (Figure 2).

\subsection{Specific development of the lid and the PV} anomaly

In order to consider the origin of the lid and the PV anomaly, we present three-dimensional back trajectories calculated by the British Atmospheric Data Centre (BADC, www.badc.ac.uk) online trajectory model. Back-trajectory analyses have been used on many occasions, successfully uncovering the source of air parcels for locations as wide-ranging as Greenland (Kahl et al., 1997) and the Antarctic (Russell et al., 2004). The BADC model is driven by operational ECMWF analyses at sixhourly intervals extracted on a $1.125^{\circ}$ latitude-longitude grid. It uses a parcel-advection scheme, summarized by Dritschel (1989) and Norton (1994), using all three wind 

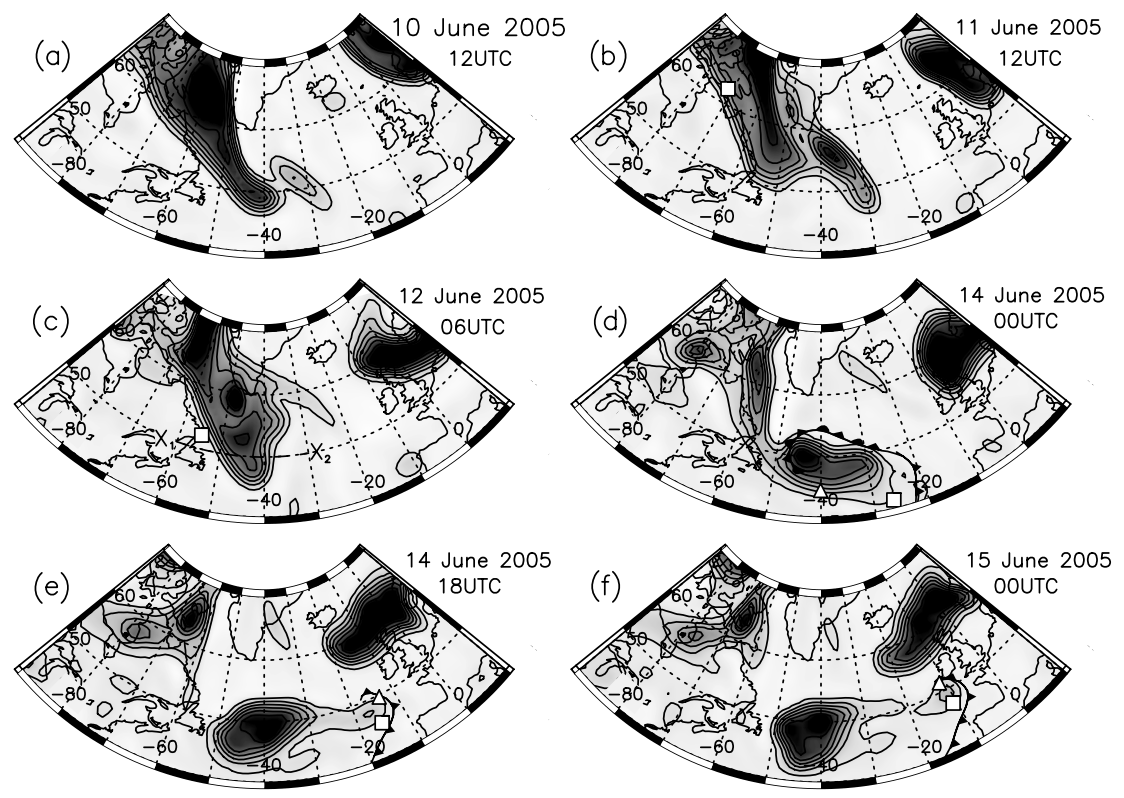

Figure 10. A selection of ECMWF operational analysis PV data on the $315 \mathrm{~K}$ isentropic surface for the build-up to the small PV anomaly moving over the UK on 15 June 2005. The contour interval is 1 PVU (i.e. $1.0 \times 10^{-6} \mathrm{~m}^{2} \mathrm{~s}^{-1} \mathrm{~K} \mathrm{~kg}^{-1}$ ); darker shading indicates higher PV. The location of the front of importance to this case is shown on panels (d)-(f). The position of this front was derived from the UK Met Office frontal analyses. The dashed line $\mathrm{X}_{1}-\mathrm{X}_{2}$ on panel (c) shows the location of the vertical cross section plotted in Figure 13. The squares and triangles relate to the trajectory position for the lid and the upper-level PV anomaly respectively, as taken from Figure 12.

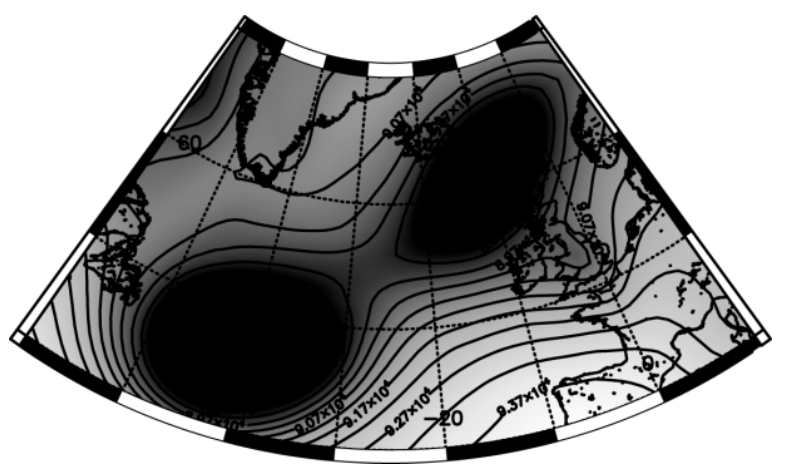

Figure 11. Geopotential height on the $300 \mathrm{hPa}$ pressure surface of the ECMWF operational analysis for 15 June 2005 at 1200 UTC. The contour interval is $500 \mathrm{~m}^{2} \mathrm{~s}^{-2}$; darker shading indicates lower geopotential height.

components. Vertical levels decrease in resolution with increasing height above the surface, and linear interpolation in pressure is used for intermediate heights.

Figure 12, showing clusters of back trajectories initiated from the location and height of the lid, indicates that the air from which it formed descended underneath the jet stream in the breaking Rossby wave over the Atlantic three or four days before IOP1. A vertical cross section of PV through the breaking Rossby wave at this time (Figure 13) delineates the fold at around $50^{\circ} \mathrm{W}$. Confirmation of the presence of this fold, and the flow of air from it, is afforded by the very dry, stable layer shearing from northwesterly to northerly at around $750 \mathrm{hPa}$ seen in a sounding from St John's, Newfoundland $\left(47.6^{\circ} \mathrm{N}\right.$, $52.8^{\circ} \mathrm{W}$ ) at 0000 UTC on 12 June 2005 (not shown). Furthermore, as the air parcel that eventually formed the lid was beginning its journey towards the UK, the ECMWF operational analyses show that the region from which these trajectories originated (9 June 2005, 1200 UTC, $74.0^{\circ} \mathrm{N}, 74.0^{\circ} \mathrm{W}, 400 \mathrm{hPa}$ ) had a PV of approximately 1.5 PVU. From the tephigrams presented earlier (Figure 4), we can also determine that air of that temperature and humidity at that level in the troposphere would have descended from at least $400 \mathrm{hPa}$, as the trajectories also show. The combination of these factors, along with the dryness and relatively high PV of this feature over the UK (see Section 3), corroborates our theory of a layer of upper-level air flowing down from the tropopause region, and fanning out from the fold - a process described by Danielsen $(1964,1968)$, and discussed in greater detail in Section 1 - and eventually moving in behind a surface front as the dry intrusion (Browning, 1997).

Figure 12 also shows that back trajectories from the upper-level trough at $280 \mathrm{hPa}$ had remained at approximately the same altitude for the previous seven days. These trajectories show the air being drawn into the jet stream over North America on 12 June 2005, before passing through the breaking Rossby wave, into the $\mathrm{COL}$ and then towards the UK in the upper-level PV anomaly (see Figure 10). From 12 June until the baroclinic development of the upper-level trough on the flank of the main COL on 14 June, the upper-level trajectories travelled much more quickly than those that formed the lid. Thenceforth, the two sets moved together, as the front (shown in Figure 10(d-f)) formed the leading edge of the 


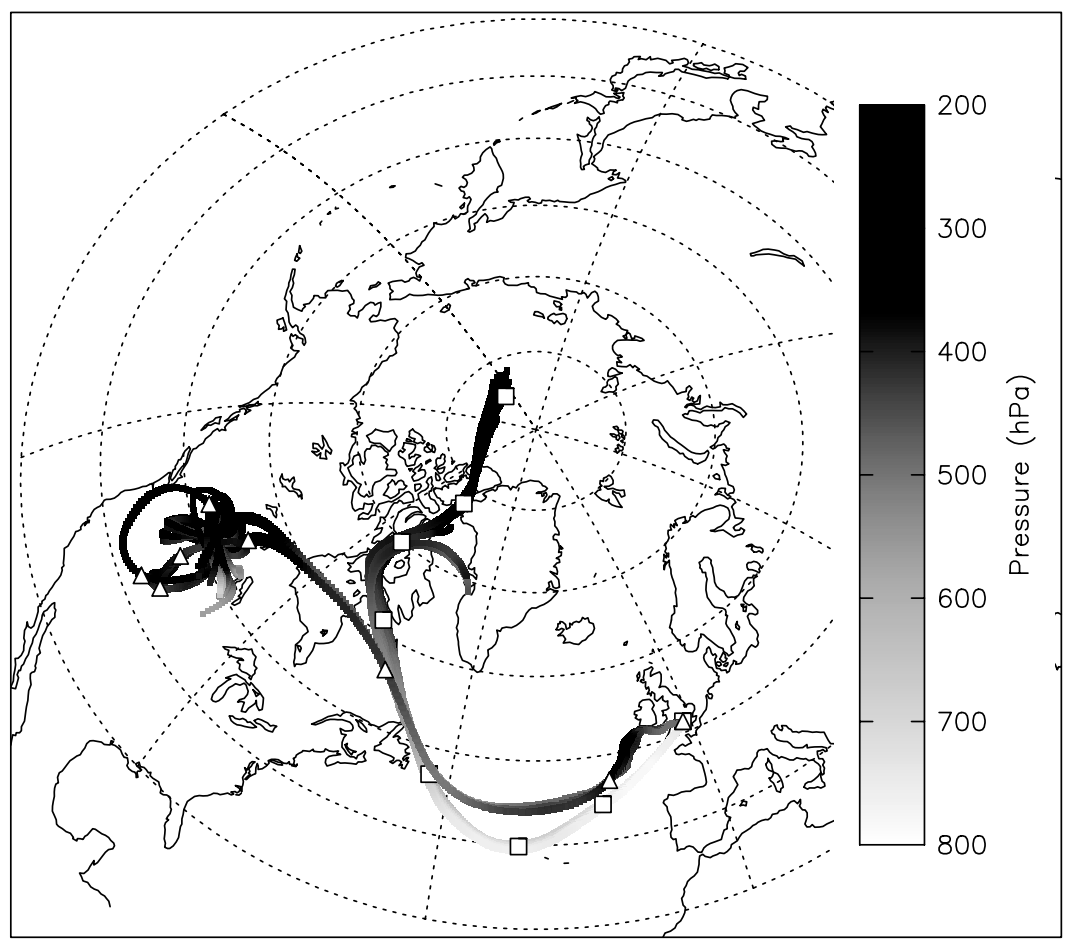

Figure 12. Two clusters of seven-day back trajectories initiated at $1200 \mathrm{UTC}$ on 15 June 2005 from $725 \mathrm{hPa}$ and $280 \mathrm{hPa}$ above Larkhill. Each cluster consists of 15 trajectories: initial latitude and longitude $\pm 5 \mathrm{~km}$ at initial elevation $\pm 10 \mathrm{hPa}$. The shade of the trajectories is indicative of their elevation: darker colours relate to higher elevations. The white squares (triangles) indicate trajectory positions at 1200 UTC on each of the seven days for one trajectory in the $725 \mathrm{hPa}(280 \mathrm{hPa})$ cluster. These symbols are also plotted on Figure 10 to show trajectory positions relative to the breaking Rossby wave.

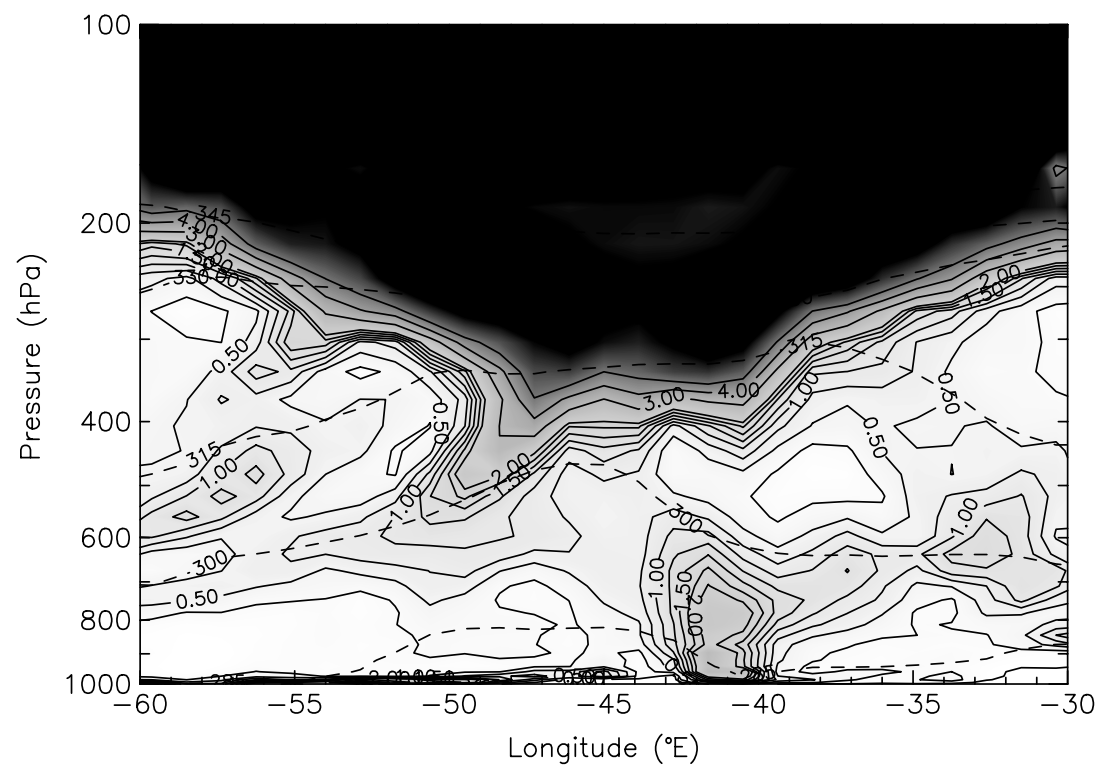

Figure 13. Vertical cross section through $50^{\circ} \mathrm{N}$ of PV, from the ECMWF operational analyses for $0600 \mathrm{UTC}$ on 12 June 2005: see line $\mathrm{X}_{1}-\mathrm{X}_{2}$ on Figure 10(c) for location. The contour intervals are 0.25 PVU for 0-2 PVU and 1 PVU for 2-5 PVU. Darker shading indicates higher PV; the maximum is about 9 PVU. Potential temperature $\theta$ (in K) has also been plotted, for comparison with Figure 10. Note that the region of high $\mathrm{PV}$ centred on $-41^{\circ} \mathrm{E}, 800-1000 \mathrm{hPa}$, was produced diabatically through a precipitation event and is not related to the stratospheric features being investigated. The trajectory of the lid at this point was at around $580 \mathrm{hPa}$ and $-55^{\circ} \mathrm{E}$, i.e. it is consistent with flow down the fold.

PV anomaly, with the remnants of the original tropopause fold (Figure 13) following behind it, forming the dry lid. It is also seen that the COL and the small PV anomaly inherited the folded structure of the original breaking Rossby wave (Figure 3), as implied in Section 3.

\subsection{Summary}

In this section we have considered the processes linking the small upper-level PV anomaly and the dry lid observed over the UK on 15 June 2005. We have 
confirmed that both were derived from stratospheric or upper-tropospheric features by showing how they were related to the same breaking Rossby wave that set up a COL over the Atlantic. The lid originated from the tropopause fold associated with the initial streamer over the western Atlantic: upper-level air descended and travelled eastward around the COL at low levels. Baroclinic development generated the upper-level PV anomaly as a shallow trough propagating along the jet stream behind a surface front, drawing the fold in behind it. Despite the fact that the dry air that eventually formed the lid formed from the same breaking Rossby wave as, and propagated over the UK together with, the upperlevel PV anomaly, the former started its journey towards the UK approximately two days before the latter.

\section{Discussion}

The aim of this case study was to investigate the impacts of, and the links between, a small upper-level PV anomaly and a dry lid observed during IOP1 of CSIP. The primary result of this work is the demonstration that the lid, which was responsible for inhibiting convection over much of southern England, originated from a tropopause fold related to the same breaking Rossby wave that spawned the upper-level PV anomaly. As noted above, previous studies of convective events have identified the simultaneous passage of a PV anomaly with a dry lid beneath it. We argue in this case that the association was not mere coincidence, as the baroclinic development of the small upper-level trough drew in the air from the fold around the COL situated over the Atlantic. It is an interesting dichotomy that the generation process and passage of an upper-level trough can, on the one hand, promote convection through the stretching of air columns by the upper-level PV anomaly, and on the other hand, inhibit convection through the dry lid, produced by the same breaking Rossby wave. Further work is in progress on other CSIP case studies to find out how common this association may be.

In Section 1 we discussed how atmospheric lids are important both in the suppression of convection and in allowing CAPE to accumulate beneath them, in the development of convective storms. In this case the degree to which the upper-level (or upper-levelderived) elements of this development process were intertwined is again highlighted by the fact that ascent ahead of a tropopause depression can be, and often is, responsible for the partial removal of a lower-level lid. This emphasizes the importance of gaining a deeper understanding of the development of the observed lids in such cases, as we have done in this paper.

\section{Conclusions}

On 15 June 2005, a small upper-level PV anomaly, associated with a short-wave trough, passed over the UK. Despite favourable conditions for convection beneath the trough, only one storm actually occurred where the PV anomaly coincided with a surface convergence line. Wider convective development was suppressed by a dry stable layer at around $2.5 \mathrm{~km}$ altitude. This case was intensively observed during the CSIP, and some of these measurements have been used to investigate the role and origin of this dry layer or lid.

We find that the lid originated in a tropopause fold that occurred along the western flank of a breaking Rossby wave over the Western Atlantic five days earlier. This event produced a large COL over the central North Atlantic, around which air from the fold was drawn at low levels (cyclonic conditions extended to the surface below the COL). As the fold tracked around the low, baroclinic development along the latter's southeastern flank generated a short-wave, upper-level trough, which propagated eastward towards the UK as a small upperlevel PV anomaly behind a surface front. Remnants of the fold were advected behind the front beneath the trough, forming the lid. We therefore conclude that the PV anomaly and the lid were not associated by chance, but were linked through the dynamics of the original Rossby wave breaking and its consequent COL. Further studies are in progress to determine how common events of this kind may be.

\section{Acknowledgements}

We wish to express our gratitude to the following organizations and individuals: the British Atmospheric Data Centre (BADC) for their provision of ECMWF data, the web trajectory service and MSG images; the UK Met Office for launching extra radiosondes from Larkhill and the frontal analyses that were reproduced in Figure 10; NASA for providing their TOMS ozone data on their website (http://toms.gsfc.nasa.gov); Dr Markus Ramatschi (GeoForschungsZentrum Potsdam) for collecting and providing the GPS data that appear in Figure 3; the many participants of CSIP who helped the project run successfully; and the Natural Environment Research Council (NERC) for supporting the MST radar as a national facility and for funding CSIP.

\section{References}

Appenzeller C, Davies HC. 1992. Structure of stratospheric intrusions into the troposphere. Nature 358: 570-572.

Bennett LJ, Browning KA, Blyth AM, Parker DJ, Clark PA. 2006 A review of the initiation of precipitating convection in the United Kingdom. Q. J. R. Meteorol. Soc. 132: 1001-1020.

Bethan S, Vaughan G, Reid SJ. 1996. A comparison of ozone and thermal tropopause heights and the impact of tropopause definition on quantifying the ozone content of the troposphere. $Q$. J. R. Meteorol. Soc. 122: 929-944.

Bevis BG, Bussinger S, Herring TA, Rocken C, Anthes RA, Ware RH. 1992. GPS meteorology: remote sensing of atmospheric water vapor using the Global Positioning System. J. Geophys. Res. 97(D14): $15787-15801$.

Browning KA. 1997. The dry intrusion perspective of extra-tropical cyclone development. Meteorol. Appl. 4: 317-324.

Browning KA, Hill FF. 1985. Mesoscale analysis of a polar trough interacting with a polar front. Q. J. R. Meteorol. Soc. 111: 445-462.

Browning KA, Monk GA. 1982. A simple model for the synoptic analysis of cold fronts. Q. J. R. Meteorol. Soc. 108: 435-452. 
Browning KA, Roberts NM. 1999. Mesoscale analysis of arc rainbands in a dry slot. Q. J. R. Meteorol. Soc. 125: 3495-3511.

Browning KA, Blyth AM, Clark PA, Corsmeier U, Morcrette CJ, Agnew JL, Ballard SP, Bamber D, Barthlott C, Bennett LJ, Beswick KM, Bitter M, Bozier KE, Brooks BJ, Collier CG, Davies F, Deny B, Dixon MA, Feuerle T, Forbes RM, Gaffard C, Gray MD, Hankers R, Hewison TJ, Kalthoff N, Khodayar S, Kohler M, Kottmeier C, Kraut S, Kunz M, Ladd DN, Lean MW, Lenfant J, Li Z, Marsham J, Mcgregor J, Mobbs SD, Nicol J, Norton E, Parker DJ, Perry F, Ramatschi M, Ricketts HMA, Roberts NM, Russell A, Schulz H, Slack EC, Vaughan G, Waight J, Wareing DP, Watson RJ, Webb AR, Weiser A. 2007. The Convective Storm Initiation Project. Bull. Am. Meteorol. Soc. 88: 1939-1955.

Clark PA, Lean H. 2006. 'An overview of high resolution UM performance for CSIP cases'. JCMM Internal Report, No. 155, $42 \mathrm{pp}$.

Danielsen EF. 1964. 'Project Springfield Report'. Defense Atomic Support Agency, Washington DC 20301, DASA 1517 (NTIS\#AD607980), 99 pp.

Danielsen EF. 1968. Stratospheric-troposheric exchange based on radioactivity, ozone and potential vorticity. J. Atmos. Sci. 25 $502-518$.

Dritschel DG. 1989. Contour dynamics and contour surgery: numerical algorithms for extended, high-resolution modelling of vortex dynamics in two-dimensional, inviscid, incompressible flows. Comput. Phys. Rep. 10: 77-146.

Emanuel KA. 1994. Atmospheric Convection. Oxford University Press: New York.

Fehlmann R, Quadri C, Davies HC. 2000. An Alpine rainstorm: sensitivity to the mesoscale upper-level structure. Weather and Forecasting 15: 4-28.

Gage KS, Green JA. 1981. Evidence for specular reflection from monostatic VHF radar observations of the stratosphere. Radio Sci. 13: $991-1001$

Griffiths M, Reeder MJ, Low DJ, Vincent RA. 1998. Observations of a cut-off low over southern Australia. Q. J. R. Meteorol. Soc. 124 $1109-1132$.

Griffiths M, Thorpe AJ, Browning KA. 2000. Convective destabilization by a tropopause fold diagnosed using potential-vorticity inversion. Q. J. R. Meteorol. Soc. 126: 125-144.

Heath DF, Krueger AJ, Roeder HA, Henderson BD. 1975. The solar back-scatter ultraviolet and total ozone mapping spectrometer (SBUV/TOMS) for Nimbus G. Opt. Eng. 14: 323-331.

Hill FF, Browning KA. 1987. Case study of a persistent mesoscale cold pool. Meteorol. Mag. 116: 297-309.
Hoskins BJ, McIntyre ME, Robertson AW. 1985. On the use and significance of isentropic potential vorticity maps. Q.J.R. Meteorol. Soc. 111: 877-946.

Juckes M, Smith RK. 2000. Convective destabilization by upper-level troughs. Q. J. R. Meteorol. Soc. 126: 111-123.

Kahl JDW, Martinez DA, Kuhns H, Davidson CI, Jaffrezo JL, Harris JM. 1997. Air mass trajectories to Summit, Greenland: a 44-year climatology and some episodic events. J. Geophys. Res. 102(C12): 26861-26875.

McCaul EW, Weisman ML. 2001. The sensitivity of simulated supercell structure and intensity to variations in the shapes of environmental buoyancy and shear profiles. Mon. Weather Rev. 129: 664-687.

Morcrette CJ, Lean H, Browning KA, Nicol J, Roberts N, Clark PA, Russell A, Blyth AM. 2007. Combination of mesoscale and synoptic mechanisms for triggering of an isolated thunderstorm: a case study of CSIP IOP 1. Mon. Weather Rev. 135: 3728-3749.

Muschinski A, Wode C. 1998. First in situ evidence for coexisting submeter temperature and humidity sheets in the lower free troposphere. J. Atmos. Sci. 55: 2893-2906.

Norton WA. 1994. Breaking Rossby waves in a model stratosphere diagnosed by a vortex-following coordinate system and a technique for advecting material contours. J. Atmos. Sci. 51: 654-673.

Norton EG, Vaughan G, Methven J, Coe H, Brooks B, Gallagher M, Longley I. 2006. Boundary layer structure and decoupling from synoptic scale flow during NAMBLEX. Atmos. Chem. Phys. 6: 433-445.

Roberts NM. 2000. 'The relationship between water vapour imagery and thunderstorms'. JCMM Internal Report, No. 110, 40 pp.

Russell A, McGregor GR, Marshall GJ. 2004. An examination of the precipitation delivery mechanisms for Dolleman Island, eastern Antarctic Peninsula. Tellus 56A: 501-513.

Schmetz J, Pili P, Tjemkes S, Just D, Kerkmann J, Rota S, Ratier A. 2002. An introduction to Meteosat Second Generation (MSG). Bull. Am. Meteorol. Soc. 83: 977-992.

Thorncroft CD, Hoskins BJ, McIntyre ME. 1993. Two paradigms of baroclinic-wave life cycle behaviour. Q. J. R. Meteorol. Soc. 119: $17-55$.

Vaughan G. 2002. The UK MST radar. Weather 57: 67-73.

Vaughan G, Price JD, Howells A. 1994. Transport into the troposphere in a tropopause fold. $Q$. J. R. Meteorol. Soc. 120: 1085-1103.

Vaughan G, Howells A, Price JD. 1995. Use of MST radars to probe the mesoscale structure of the tropopause. Tellus 47A: 759-765 